\title{
Comments on "New Concerns for Neurocognitive Function during Deep Space Exposures to Chronic, Low Dose Rate, Neutron Radiation"
}

\author{
Joseph J. Bevelacqua, ${ }^{1}$ James Welsh, ${ }^{2}$ and S. M. Javad Mortazavi ${ }^{3,4}$ \\ https://doi.org/10.1523/ENEURO.0329-19.2019 \\ ${ }^{1}$ Bevelacqua Resources, Richland, Washington 99352, ${ }^{2}$ Department of Radiation Oncology, Edward Hines Jr VA \\ Hospital, Hines, Illinois 60141, ${ }^{3}$ Medical Physics Department, Shiraz University of Medical Sciences, Shiraz, IR, and \\ ${ }^{4}$ Diagnostic Imaging Department, Fox Chase Cancer Center, Philadelphia, Pennsylvania 19111
}

\begin{abstract}
Evaluations of the biological effects of space radiation must carefully consider the biological system response and the specific nature of the source term. Acharya et al. (2019) review neurocognitive function during deep space exposures to chronic, low dose rate, neutron radiation, but do not use a source term that reflects the actual space environment in terms of radiation types and their respective energies. In addition, important biological effects, including the adaptive response to the space radiation environment, are not addressed.
\end{abstract}

Key words: HZE; LET; neurocognitive function; neutrons; radiation; space

\section{Significance Statement}

Acharya et al. (2019) review neurocognitive function during deep space exposures to chronic, low dose rate, neutron radiation, but do not use a source term that reflects the actual space environment in terms of radiation types and their respective energies. In addition, important biological effects including adaptive response to the space radiation environment are not addressed.

This commentary addresses the article "New concerns for neurocognitive function during deep space exposures to chronic, low dose rate, neutron radiation" by Acharya et al. (2019). Considering the limitations of currently available technology for simulating the space radiation environment, this article (Acharya et al., 2019) outlines the use

Received August 17, 2019; accepted September 27, 2019; First published December 19, 2019.

The authors declare no competing financial interests.

Author contributions: S.M.J.M. drafted the letter. J.J.B., J.W., and S.M.J.M. reviewed and approved the manuscript.

Correspondence should be addressed to S. M. Javad Mortazavi at Mortazavismj@gmail.com.

https://doi.org/10.1523/ENEURO.0329-19.2019

Copyright (C) 2020 Bevelacqua et al.

This is an open-access article distributed under the terms of the Creative Commons Attribution 4.0 International license, which permits unrestricted use, distribution and reproduction in any medium provided that the original work is properly attributed. of a new neutron irradiation facility to simulate the low dose rates found in deep space. Their study showed neurobehavioral and electrophysiological defects in rodents subjected to continuous (6 month duration) exposure to low dose rate $(1 \mathrm{mGy} / \mathrm{d})$ neutron exposures. Despite the numerous strengths of this study, it has a few major shortcomings. The first shortcoming is due to ignoring the key point that in a realistic space environment, cells will be exposed to multiple low LET (linear energy transfer) protons before being traversed by intermediate and high-LET HZE (high charge and energy) particles. It is worth noting that a National Aeronautics and Space Administration report (Huff et al., 2016) clearly states that this sequential exposure can lead to the induction of adaptive responses in space that may significantly decrease the level of damages induced by high-LET HZE particles: "There have been several studies performed that indicate an adaptive response to low-dose ionizing radiation can 
provide a level of protection against future exposures (Bhattacharjee and Ito 2001; Mortazavi et al., 2003; Elmore et al., 2008, 2011; Rithidech et al., 2012). This may be particularly important for understanding risks in the space environment because the GCR [galactic cosmic radiation] environment is composed predominantly of protons, and it is realistic to expect that cells will be exposed to multiple hits of protons before being traversed by an HZE particle" (Huff et al., 2016). Moreover, an article authored by a large group of scientists from the United States, Canada, the United Kingdom, Russia, and Belgium have recently highlighted the cardinal role of adaptive response as an efficient method of biological protection in radiation risk reduction strategies for astronauts participating in space journeys (Cortese et al., 2018). It is worth noting that despite current controversies, some studies show cells pre-exposed to a low dose reveal decreased vulnerability to subsequent exposure to higher doses and produce a neuroprotective effect (Betlazar et al., 2016).

The second shortcoming is assuming that ${ }^{252} \mathrm{Cf}$ neutron radiation can represent the biological effects of the HZE particles in a deep space mission. In $\sim 3 \%$ of decays, spontaneous fission occurs. This yields energetic fission products along with $\sim 3.75$ neutrons per fission. The emitted neutrons are "fast" with a most probable energy of 0.7-1.0 MeV and an average energy of $2.1-2.3 \mathrm{MeV}$. Given this consideration, there are a number of issues with simulating solar particle events (SPEs) and GCR with a fission source, as follows:

1. The dominant dose component of ${ }^{252} \mathrm{Cf}$ neutrons is not equivalent to more energetic protons and HZE particles. The energy differences are orders of magnitude apart (Bevelacqua, 2008, 2017).

2. The interactions from the neutrons include elastic and inelastic scattering and a limited number of reaction channels such as (n,gamma), $(n, p)$, and (n,d; Bevelacqua, 1999, 2008, 2009, 2016). GCR and SPE open numerous higher-energy channels with the productions of pions, muons, and a host of spallation products and their associated hadronic cascades (Bevelacqua, 1999, 2008, 2009, 2016). The biological effects of these various species are not readily equated to a low-energy fission source.

3. In addition to direct reactions in tissue, the reactions with the spacecraft shell and components will vary significantly (Bevelacqua, 2008).

4. Characterizing a fission source in terms of delivered biological dose is significantly easier than determining the dose from a spectrum of protons and HZE particles of much greater energy (Bevelacqua, 2008).

5. The absorbed dose does not correspond to a biological detriment. This dose must be weighted with an appropriate factor [e.g., RBE (relative biological effectiveness), quality factor, or radiation weighting factor] to obtain a biological dose. Determining these factors is a nontrivial exercise (Bevelacqua, 2010). Using a stochastic International Commission on Radiologic Protection methodology (Bevelacqua, 1999, 2009), it is clear that energy dependence and radiation type are significant factors. Neutron factors are not the same as those for protons and HZEs.

\section{References}

Acharya MM, Baulch JE, Klein PM, Baddour AAD, Apodaca LA, Kramar EA, Alikhani L, Garcia C Jr, Angulo MC, Batra RS, Fallgren CM, Borak TB, Stark CEL, Wood MA, Britten RA, Soltesz I, Limoli $C L$ (2019) New concerns for neurocognitive function during deep space exposures to chronic, low dose rate, neutron radiation. eNeuro 6:ENEURO.0094-19.2019.

Betlazar C, Middleton RJ, Banati RB, Liu G-J (2016) The impact of high and low dose ionising radiation on the central nervous system. Redox Biol 9:144-156.

Bevelacqua JJ (1999) Basic health physics: problems and solutions. New York: Wiley.

Bevelacqua JJ (2008) Health physics in the 21st century. New York: Wiley.

Bevelacqua JJ (2009) Contemporary health physics: problems and solutions. New York: Wiley.

Bevelacqua JJ (2010) Feasibility of using internal radiationgenerating devices in radiotherapy. Health Physics 98:614-620.

Bevelacqua JJ (2016) Health physics: radiation-generating devices, characteristics, and hazards. New York: Wiley.

Bevelacqua JJ (2017) Radiation protection consequences of the emerging space tourism industry. J Earth Science 1:1-11.

Bhattacharjee D, Ito A (2001) Deceleration of carcinogenic potential by adaptation with low dose gamma irradiation. In Vivo 15:87-92.

Cortese F, Klokov D, Osipov A, Stefaniak J, Moskalev A, Schastnaya J, Cantor C, Aliper A, Mamoshina P, Ushakov I, Sapetsky A, Vanhaelen Q, Alchinova I, Karganov M, Kovalchuk O, Wilkins R, Shtemberg A, Moreels M, Baatout S, Izumchenko E, et al. (2018) Vive la radiorésistance! Converging research in radiobiology and biogerontology to enhance human radioresistance for deep space exploration and colonization. Oncotarget 9:14692-14722.

Elmore E, Lao X-Y, Kapadia R, Giedzinski E, Limoli C, Redpath JL (2008) Low doses of very low-dose-rate low-LET radiation suppress radiation-induced neoplastic transformation in vitro and induce an adaptive response. Radiat Res 169:311-318.

Elmore E, Lao X, Kapadia R, Swete M, Redpath J (2011) Neoplastic transformation in vitro by mixed beams of high-energy iron ions and protons. Radiat Res 176:291-302.

Huff J, Carnell L, Blattnig S, Chappell L, Kerry G, Lumpkins S, Simonsen L, Slaba T, Werneth C (2016) Evidence report: risk of radiation carcinogenesis. Houston, TX: National Aeronautics and Space Administration, Lyndon B. Johnson Space Center.

Mortazavi SMJ, Cameron JR, Niroomand-rad A (2003) Is the Adaptive Response an Efficient Protection Against the Detrimental Effects of Space Radiation. Proc 28th Intl Cosmic Ray Conf. Tsukuba, Japan, pp. 4299-4302.

Rithidech KN, Lai X, Honikel L, Reungpatthanaphong P, Witzmann FA (2012) Identification of proteins secreted into the medium by human lymphocytes irradiated in vitro with or without adaptive environments. Health Phys 102:39. 